\title{
Analysis of Wave Energy Conversion with Dynamic Systems Theory
}

\author{
Sorin Ciortan ${ }^{1, *}$, Eugen Rusu ${ }^{1}$ \\ ${ }^{1}$ Mechanical Engineering Department, Dunarea de Jos University of Galati Domneasca Street 111, Galati, Romania
}

\begin{abstract}
In wave energy conversion one of the most important steps is building scenarios about long term efficiency, taking into account that several factors are involved. Based on the assumption that actually the weather conditions show important modifications year by year, analyses of wave power evolution during the exploitation time range must rely on both prediction models and on several options for the conversion device. From this point of view, the wave energy conversion process can be considered a dynamic system. The dynamic system theory based methodology approach systems behaviour through relationships between systems components. Comparing to usual scientific approaches, which try to decompose the analyzed system, this methodology offers a view of entire system behaviour The paper presents a method for building scenarios of wave energy conversion, in the nearshore of the Black Sea, based on a model which includes also forecasts of the weather influence.
\end{abstract}

\section{Introduction}

Despite its enormous potential, a rough estimation would be 1TW worldwide [1], the wave energy still remains un-exploited on large scale. This situation is due to several reasons as: high values initial investment, continuous weather conditions changing - the global warming influence became year by year more important, random wave height distribution over time and, not the last or the less important - the conversion technology and devices.

There are several wave conversion technologies, based on different mechanical principles, all involving besides the mechanical part also sophisticated electronic modules [2]. The in itial investment, i.e. the device price, the price for manual installation and other expenses can reach high values.

Other aspect linked to the wave energy conversion is the random wave frequency and direction, this factor being subjected to sudden changes, following the weather changes. As consequence, there is no universal optimal converter but for each location extensive studies for establishing the best one must be conducted $[3,4]$.

The problem of wave energy converting implementation is more important for closed water areas, where the waves deliver less power than in the oceans, figure 1 . In these areas the investment into wave energy recovery must be very careful prepared, both from mechanical design and from a financial point of view. Even there are available software packages designed for making these investigations [5] the input data, are situation and location-dependent and cannot be used worldwide.
The present paper presents a methodology for analysis of wave energy conversion, with common devices, based on an original combination between dynamic systems theory with neural network predicted wave characteristics.

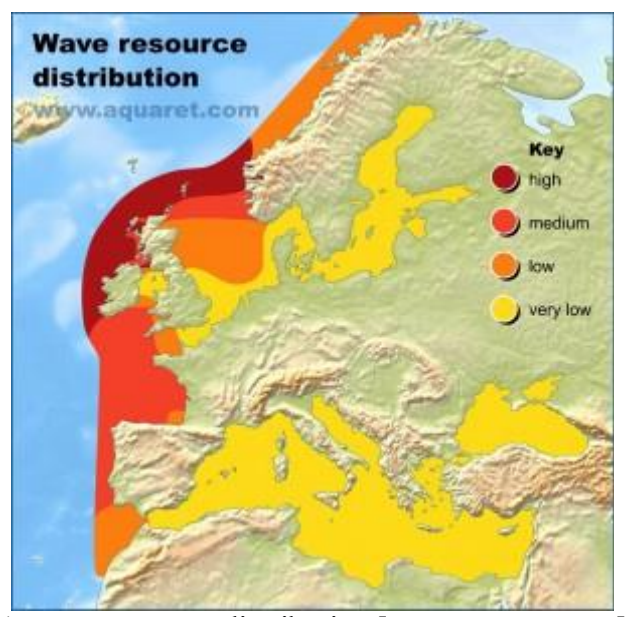

Fig. 1. Wave resource distribution [www.aquaret.com]

\section{Dynamic Systems Modeling}

The dynamic systems theory [6] states that the system's behaviour is influenced not only by the components properties but also by the relationships established between them. From this point of view the studies on a system must be performed without breaking these links, like regular scientific analys is methods recommend.

Following this theory, any system structure can be represented with few basic elements: level, rates, flows

* Corresponding author: sorin.ciortan@ugal.ro 
and constants. Each element have a specific role into the systemmodeling:

- Levels contain variable values.

- Rates performs flow control.

- Flows make the links between elements

- Constants contain constant values

. The systems limits are represented by boundary conditions. Based on these components the system structure is built and the appropriate relationships are imposed through an equation editor.

Due to its particularities, the dynamic systems method is very suitable for modeling and simulation of large scale systems involving world energy dynamics [7], climate changing [8], their impact on human life $[9,10]$ and the human activities impact on biosphere [11].

There are several dedicated software for systems modeling. In the present paper the Vensim software [12] was used.

\subsection{Wave energy conversion model building}

In order to build a model for the wave energy conversion, the first step is to identify the appropriate system and make the corresponding correlation with the basic elements presented above.

Based on the energy flow - from the wave to the converting device - in the system two level elements are included, one for the wave energy and second for the converted energy.

The wave energy component is feed with energy by waves through a rate element - wave power, and is discharged by another rate element - converter. The last one feeds with electrical power the converted energy level element. As a result, the base model for the wave energy systemmodel is built, figure 2 .

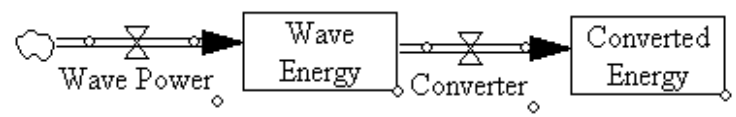

Fig. 2. Wave energy conversion system base model

The second step in the model build ing is establishing of mathematical equations that drive the system. Taking into account that the waves have a random behaviour, for computing the available power on wave crest length, the model presented in [13] was used, equation 1.

$$
P_{n}=\rho g^{2} H_{S}^{2} T_{E} / 64 \pi
$$

where:

$P_{n}$ - wave power per wave crest length $(\mathrm{W} / \mathrm{m})$

$\rho$ - sea water density $\left(1.023 \mathrm{~kg} / \mathrm{m}^{3}\right)$

$g$ - gravitational acceleration $\left(9.8 \mathrm{~m} / \mathrm{s}^{2}\right)$

$H_{S}$ - significant wave height (m)

$T_{E}$ - wave energy period (s)

Taking into account the variables involved in wave power mathematical model, the conversion system model must be completed with the appropriate elements. As it can be observed, besides the four elements - the backbone of the system - other components appeared, both as constants and as auxiliary variables.

The final step is linking the system components, and in this way the final diagram is obtained, figure 3.

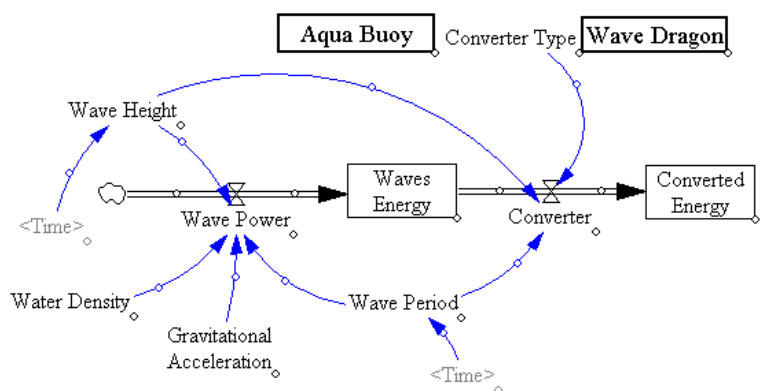

Fig. 3. Wave energy conversion system - full model

As constants, water density and gravitational acceleration were inserted into the system model. Even their values presents slightly variations following the temperature and, respectively, the global position, these can be considered as constants [13].

As auxiliary variables, significant wave height and wave period are inserted into the model, as being linked to the wave power rate variable, which feed the wave energy level one.

The links between the components of the model follow the real world correlations between the simulated systems. From this perspective, it was assumed that the wave power is generated under the simultaneous occurrence of the wave height, wave period, water density and gravitational acceleration. Meanwhile, the wave height and wave period are functions of time, at each time step (day) having different values.

On the other hand, wave height has an influence on converter, since the converting devices work only below some specific wave height values. As a consequence, in the converter equation a conditional limiting function must be used.

The converter type is an auxiliary Boolean variable used to trigger between the converting device types, since in this model only two devices were used. In order to choose one or another device, in the converter equation a conditional function was used.

\subsection{Wave energy conversion model inputs}

Once built, the wave energy model can be used for simulation of the wave power conversion to electrical power and for creation and analy ze of different scenarios, based on different converting devices, different wave conditions etc.

For performing simulation, some inputs are needed: time line of the simulation, wave characteristics significant wave height and wave period, converting device characteristics - generated power as a function of wave height and wave period.

The system evolution is time dependent. As consequence, the beginning and ending of simulation must be defined. The Vensim software has a built in variable (time) allowing simulation control from this point of view. The time line considered was one year, 
with a day as time step. In order to simplify the graphic representation of the system, the time is declared as shadow variable and, as a consequence, will appear multiplied into the model diagram.

The wave characteristics, in order to take into account the weather forecasted influence, are obtained by neural network prediction, based on previous records for the targeted location [14]. In the present paper a location near the Romanian Black Sea shore was considered and the prediction input data for the neural model were records corresponding to previous years. The results obtained are inserted into the wave energy systemmodel as lookup tables, with daily values.

The converting device characteristics are obtained based on specific technical data tables. In the present paper two devices were considered: Aqua Buoy, as an offshore recommended device with a $250 \mathrm{~kW}$ maximum converted power and Wave Dragon, as an intermediate water recommended device, with a $7 \mathrm{MW}$ maximum converted power. Only one device of each type was considered.

In order to transform the technical data of the chosen devices into mathematical correlations, usable in system's model, a regression procedure was used. With this purpose, the power matrix of selected devices [15] were imported in Datafit software and subjected to a regression procedure, with two independent variables (wave significant height and wave period) and one dependent variable - converted energy. As results, the converted power - significant wave height - wave period dependencies were obtained, as polynomial equations. These equations will be inserted into the model using the built-in equation editor of Vensim.

In figures 4 and 5 are graphically presented the converting characteristic for the Aqua Buoy and, respectively for the Wave Dragon devices.

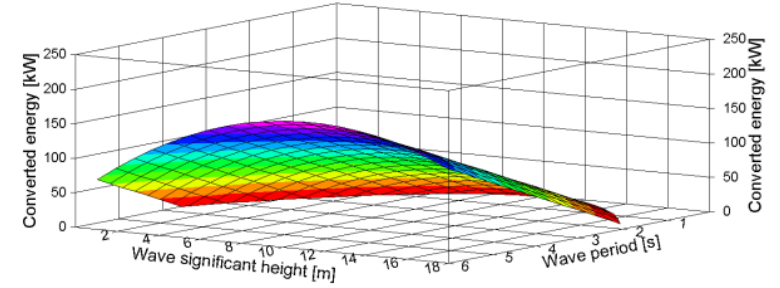

Figure 4. Aqua Buoy converter characteristic

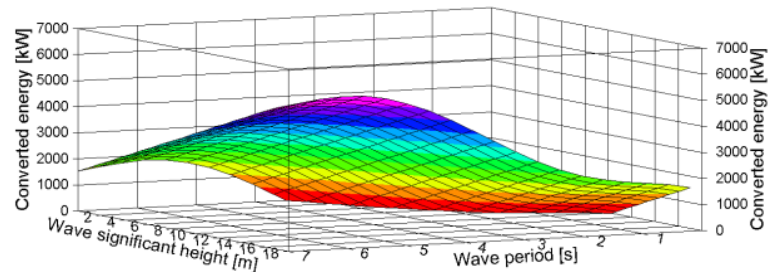

Fig. 5. Wave Dragon converter characteristic

During a simulation cycle, the wave energy level element will cumulate the energy amount provided by waves while the converted energy level element will cumulate the amount of converted energy delivered by the converting device. The converter element is controlling the energy flow from waves energy to converted energy

\section{Discussion}

After running a simulation, several information are available. In figure 6 the wave characteristics are presented, obtained by neural network prediction and in figure 7 the simulated results for generated wave power are shown.

In figure 6 it can be observed that during the JanuaryMarch period the significant wave height is higher, leading also to a higher wave power, with a value of approx $9.4 \mathrm{~kW}$ (figure 7). A lso, in this period some power peaks (approx. $80 \mathrm{~kW}$ ) are observed, but for a very short time - days 25, 36 - due to storm generated waves. Higher values of wave power did also occur in the period October-December, with an average value of approx. $5 \mathrm{~kW}$. In the warm period (April-September) the average value of the wave power is low (approx. $2 \mathrm{~kW}$ ). As a consequence, the average value of the wave power over entire year, in the selected location, is approximately $4 \mathrm{~kW}$. All above presented values are consistent with those found by other researchers [16] and proof that the Black Sea wave power potential is relative low, especially near Romanian shore.

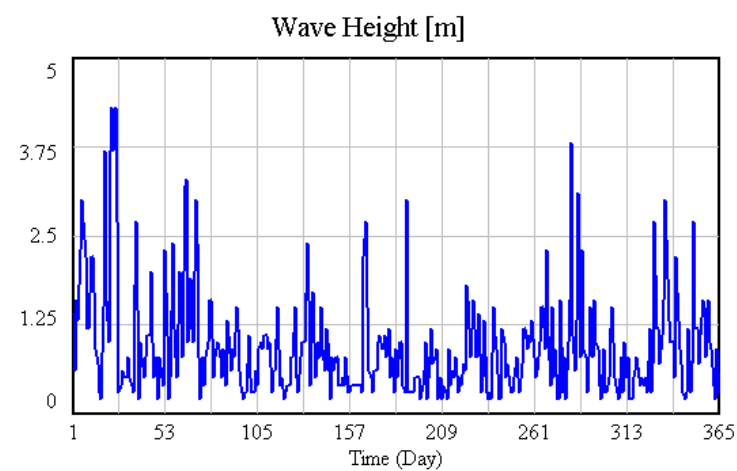

a)

Wave period [s]

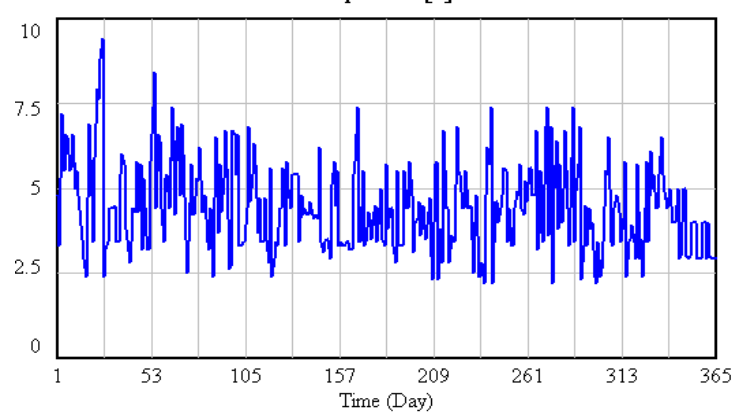

b)

Fig. 6. Predicted wave characteristics a) significant height; b) period;

If the daily wave energy over one year are cumulated, (figure 8), the total potential available for the simulated period is obtained: approx. 1.5 MWh.

The simulation results will be presented in a comparative way: Aqua Buoy versus Wave Dragon. 


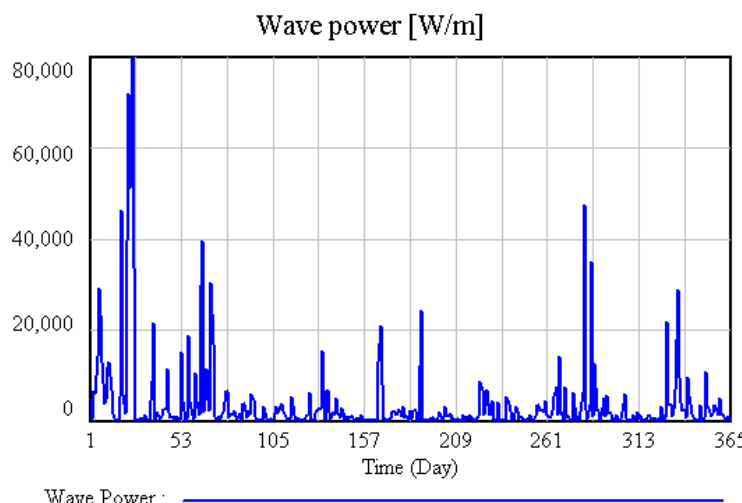

Fig. 7. Wave power generated daily during the simulation time

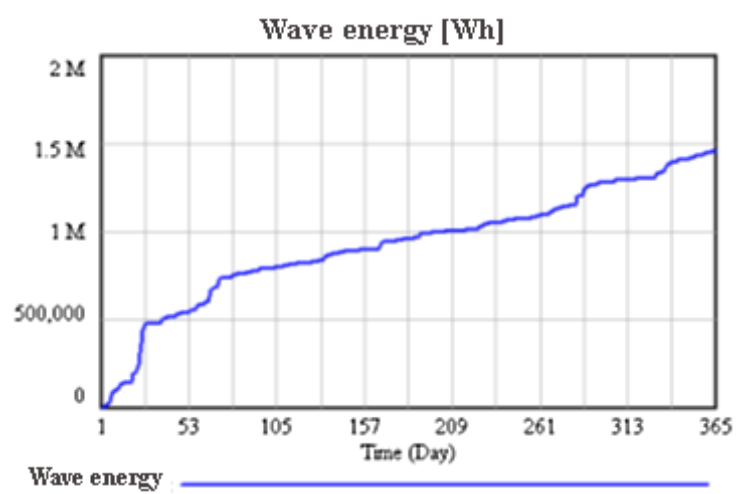

Fig. 8. Wave energy generated cumulated over one year

In figure 9 are presented the performances of those two devices, considered as amount of converted power from wave available power (figure 7). As can be seen, the Wave Dragon device succeed to convert a larger amount comparing with Aqua Buoy one.

Figure 10 shows the comparis on of the cumulated converted energy between the devices. Due to the difference of values, two Y-axis scales were used: one with $20 \mathrm{kWh}$ top value and one with $2 \mathrm{MWh}$ top value.

Looking now at figure 10, it can be observed that the cumulated amount of the converted energy by Aqua Buoy device, during the whole year, is approximately $10 \mathrm{kWh}$, corresponding to an average value of 0.03 $\mathrm{kWh} /$ day.

The Wave Dragon device shows a better conversion rate - approximately $3.2 \mathrm{kWh} /$ day - lead ing to cumulated converted energy of about 1.2MWh over whole year.

As a consequence, if the Aqua Buoy device is used, a difference of approximately $1 \mathrm{MWh} /$ year of energy will be unused and, therefore lost. If the Wave Dragon device will be used, the unused quantity of energy will be only approx.0.3MWh/year.

If it is compulsory to use the Aqua Buoy device, in order to convert as much is possible from the generated wave energy, the solution is to use several devices. In figure 11 it is presented a comparison regarding the converted amount between one Wave Dragon and 50, 100 and 140 Aqua Buoy devices, parallel mounting. Taking into account that a Wave Dragon device's price is around 14238652 Euro and an Aqua Buoy device price is around 169507 euro [17], following the information from figure 11, the conclusion is that a Wave Dragon device can be replaced, from converted energy point of view, with 110 Aqua Buoy devices.

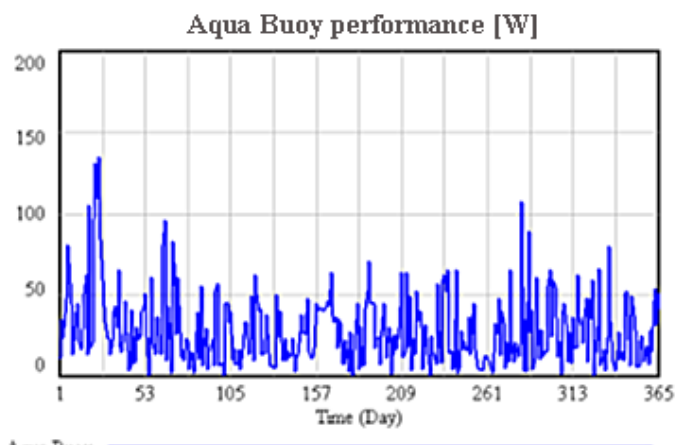

B Aqua Buoy

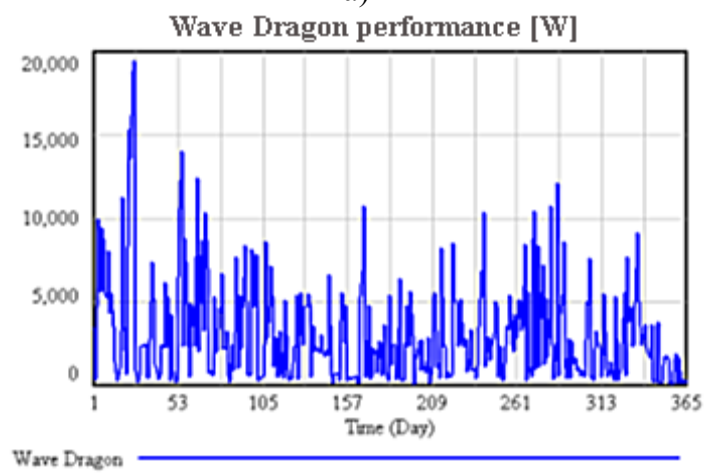

b)

Fig. 9. Wave converter performance a) Aqua Buoy; b) Wave Dragon

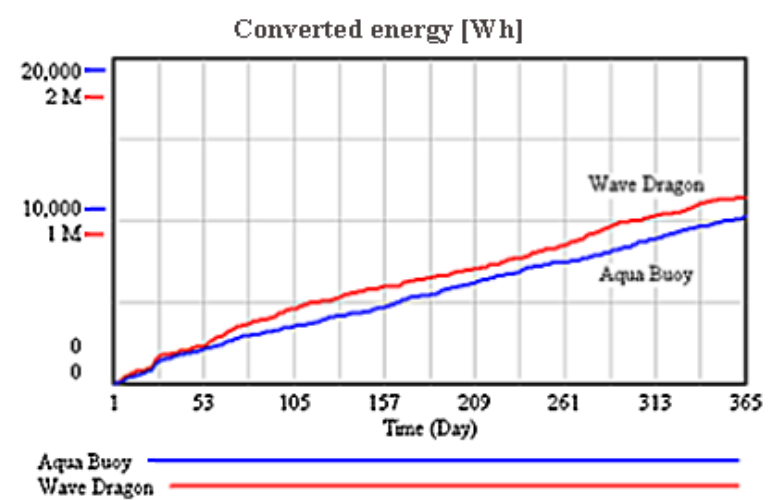

Fig. 10. Aqua Buoy vs Wave Dragon converted power

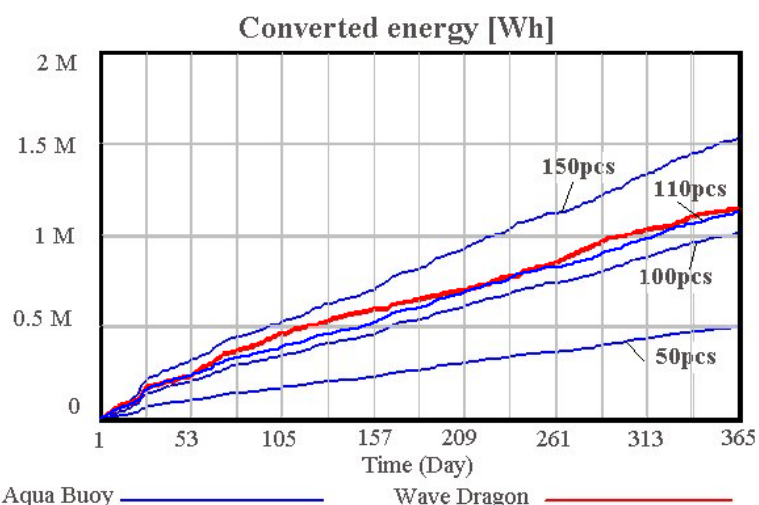

Fig. 11. Wave energy over one year converted by several Aqua Buoy(50,100,110,150 pieces) - one Wave Dragon devices 
Following the amount of the wave energy available, further solutions can be investigated, as the using of other converter type as Pelamis (around 2638520 Euro) for example [18].

\section{Conclusions}

Taking into account all presented above, some conclusions can be drawn:

- In order to convert wave energy, which have an enormous potential, several converting devices are available. As these devices presents different performances and costs, any attempt to transform the wave energy into electricity should be preceded by a modeling procedure, allowing the optimization of device selection and predictions of converting devices performances, especially when the target area is located in enclosed seas, as Black Sea, Mediterranean Sea, Baltic Sea etc.

- In order to design an efficient wave energy converting station, some simulations must be performed also for weather prediction, linked to the spotted area.

- The dynamic system theory, allowing to simulate systems not only by components, but also with links between them, is a suitable tool for building models of wave energy conversion systems, with the goal to simulate the behaviour of these and take the appropriate decisions.

- A way to improve the models accuracy, offering this way a better view of future converting station behaviour, in weather changing conditions, is the combination of dynamic system theory with the neural network based prediction method. In this purpose, the neural network model must be accordingly trained and validated [14]

- In the present study, using dynamic systems simulation and neural network prediction, the evolution of wave energy conversion was analyzed, using two converting devices (Aqua Buoy and Wave Dragon), during one year. It was found, comparing the values presented in figures 8 and 10, that the best wave energy converting device for target location (the near shore of the Black Sea), taking into account the weather conditions is the Wave Dragon converter, as this one succeeds to transform $80 \%$ of the available cumulated wave energy during one year. The Aqua Buoy device, in the same period succeeded to convert only $15 \%$ from the available wave energy.

\section{Acknowledgement}

This work is carried out in the framework of the research project REMARC (Renewable Energy extraction in MArine environment and its Coastal impact), supported by the Romanian Executive Agency for Higher Education, Research, Development, and Innovation Funding - UEFISCDI, grant number PN-III-P4IDPCE-2016-0017

\section{References}

1. J. Falnes., Marine Structures, 20, (2004)

2. B. Drew, A.R. Plummer, M.N. Sah inkaya, Proc. IMEchE, 223, (2009)

3. J.P. Kofoed, P. Frigaard, M. Kramer, The Renewable Ocean Energy Utilization, (2006)

4. D. Jarocki, Wave Energy Converter Performance Modeling and Cost of Electricity Assesment (2010)

5. Invest, http://data.naturalcapitalproject.org/invest$\underline{\text { releases/ }}$

6. J.M. Garcia, System Dynamic - Exercises (2014)

7. S.A.R.M.M Kooshknow, An Exploratory Model to Investigate the Dynamics of the World Energy System, (2013)

8. A. Ford, Global Warming and System Dynamics, (2007)

9. S.P. Simonovic, Understanding Climate Change from Data, (2012)

10. A.S. Momodu, L.Kivuti-Bitok, AAS Open Research, (2018)

11. L. Wen, L. Bay, E. Zhang, Envron. Eng, Res.21(4): 355-364, (2016)

12. Ventana Systems inc., www.vensim.com

13. A.M. Cornett, Proc. ISOPE, (2008)

14. S. Ciortan, E. Rusu, Proc. ICACER, (2018)

15. D. Silva, E. Rusu, C.G. Soares, Energies, 6, 13441364, (2013)

16. L. Rusu, Energies, 8, 10370-10388, (2015)

17. E. Rusu, F. Onea, Clean Energy, 2 (1), 10-19, (2018)

18. C. Bosserelle, S. Reddy, J. Kruger, Cost analysis of wave energy in the Pacific, (2015) 